\title{
SISTEM PELAYANAN KEPENDUDUKAN RT 002 RW 012 LUBANG BUAYA
}

\author{
Samsul Hasan ${ }^{1}$, Ambar Tri Hapsari ${ }^{2}$, Abdul Mufti ${ }^{3}$ \\ Program Studi Teknik Informatika, Fakultas Teknik dan Ilmu Komputer, \\ Universitas Indraprasta PGRI \\ Jalan Raya Tengah No 80, Kelurahan Gedong, Pasar Rebo, Jakarta Timur \\ Samsulhasan2007@gmail.com¹, mambar.trihapsari@gmail.com², abdul.mufti@gmail ${ }^{3}$
}

\begin{abstract}
Abstrak
Sistem informasi kependudukan merupakan sistem yang mempunyai peran sangat penting dalam pemerintahan dan pembangunan penyelenggaraan data kependudukan untuk pemenuhan hak dari setiap warga negara.Agar sejalan dengan arah penyelenggaraan pendataan penduduk, maka pendaftaran penduduk dan pencatatan sipil sebagai sub pilar kependudukan perlu ditata dengan sebaik-baiknya. Maka perlu adanya sistem atau aplikasi untuk mempermudah pendataan kependudukan yang efektif dan efisien untuk mengurangi kesulitan pendataan dan pencarian data. Peneliti bertujuan untuk merancang sistem aplikasi informasi yang mengubah dari proses manual kebentuk kompoterisasi dan merancang pencarian data kependudukan yang lebih cepat. Peneliti menggunakan metode waterfall, dan hasil dari penelitian dapat mempermudah dalam proses kegiatan pelayanan permohonan surat-surat kependudukan serta mempercepat proses pengumpulan data.
\end{abstract}

Kata Kunci: Sistem Aplikasi, Kependudukan

\begin{abstract}
Population information system is a system that has a very important role in the government and development of the implementation of population data for the fulfillment of the rights of every citizen. In order to be in line with the direction of the implementation of population data collection, the registration of residents and civil registration as a sub-pillar of the population needs to be organized as well as possible. Therefore, it is necessary to have a system or application to facilitate effective and efficient population data collection to reduce the difficulty of data collection and search. Researchers aim to design information application systems that transform from a manual process to a comparative form and design faster search of population data. Researchers use waterfall method, and the results of the research can facilitate the process of service activities of requesting letters of residence and accelerate the process of data collection
\end{abstract}

Keyword: System Application, Population

\section{PENDAHULUAN}

Sistem informasi kependudukan merupakan sistem yang mempunyai peran sangat penting dalam pemerintahan dan pembangunan penyelenggaraan data kependudukan yang diarahkan pada pemenuhan hak dari setiap warga negara. Sejalan dengan arah penyelenggaraan pendataan penduduk, maka pendaftaran penduduk dan pencatatan sipil sebagai sub pilar kependudukan perlu ditata dengan sebaik-baiknya, agar dapat memberikan manfaat dalam perbaikan dimana pengelolaan data penduduk merupakan tanggung jawab Pemerintahan Kabupaten/Kota dalam pelaksanaannya diawali dari RT/RW/Kelurahan dan Kecamtan selaku ujung tombak pendataan penduduk. Wilayah RT 002 RW 012 Lubang Buaya-Jakarta Timur selama ini mempunyai sistem informasi masih dalam bentuk manual sehingga memperlambat dalam prose penambahan, perubahan maupun penghapusan data serta pendataan daftar calon penduduk Berdasarkan uraian diatas, maka peneliti akan mengangkat judul " Rancangan Sistem Aplikasi Kependudukan Di RT.002 Rw.012 Lubang Buaya-Jakarta Timur. Peneliti merancang dan membuat sisitem informasi kependudukan yang efektif dan efisien untuk mengurangi kesulitan dalam pencarian data. Alpikasi ini dirancang untuk dapat mengubah proses yang sebelumnya manual ke proses komputerisasi dan dapat membuat pencarian data kependuduk menjadi lebih cepat. 


\section{PENELITIAN RELEVAN}

Penelitian relevan dari (Kahfi, 2014). Perancangan Aplikasi Data Penduduk RT 04 RW 008 Perumahan Kemang Swatama Depok. Penelitian yang dilakukan ini sangat bermanfaat bagi petugas RT dimana dapat membantu mempercepat dan mengefisienkan waktu proses pengolahan data, serta mengurangi terjadinya kesalahan pada saat input data penduduk. Serta memberikan kemudahan karena sudah terkomputerisasi, dimana sebelumnya pengolahan data yang dilakukan masih menggunakan cara manual. Banyak resiko yang dapat terjadi diantaranya salah input data penduduk, data yang masih menggunakan kertas dapat hilang, terbakar, ataupun basah. Oleh sebab itu sangat tepat jika perancangan ini di aplikasikan di wilayah tersebut.

Penelitian relevan dari (Nurizal, 2014). Sistem Informasi Data Kependudukan dan Administrasi Di Kelurahan Curug Kecamatan Cimanggis. Dengan era revolusi 4.0 perlahan semua semua pemenuhan kebutuhan sudah beralih ke digital. Sehingga interaksi manusia dan teknologi sudah tidak terelakan lagi, begitupun di pendataan penduduk yang seharusnya sudah tidak menggunakan cara manual lagi dan beralih ke digital. Sehingga pekerjaan menjadi lebih cepat dan mengurangi kesalahan yang akan terjadi seperti duplikasi data.

\section{METODE PENELITIAN}

Metode yang digunakan oleh peneliti dalam penelitian adalah metode grounded (gronded research) yaitu metode penelitian berdasarkan fakta dan menggunakan analisis perbandingan dengan tujuan mengadakan generalisasi empiris, menetapkan konsep, mengembangkan teori, pengumpulan dan analisis data dalam waktu yang bersamaan.

Teknik pengumpulan data yang digunakan dalam penelitian ini dilakukan dengan 2 cara yaitu observasi/pengamatan langsung dilapangan dengan cara mengamati agar data yang dikumpulkan akurat untuk bahan penelitian dan wawancara/interview seperti menanyakan tentang pencatatan penduduk yang berutujuan untuk mengetahui apakah sudah modern atau masih manual.

Langkah-langkah pengembangan sistem

Model pengembangan sistem yang digunakan pada penelitian ini adalah modem Waterfall atau model sekuensial linier yang terdiri dari beberapa tahapan sebagai berikut :

a. Analisa kebutuhan sistem. Dilakukan untuk mengetahui dan memahami kebutuhan pengguna.

b. Studi kepustakaan. Untuk mencari refrensi dan berbagai diskusi pembahasan yang berhubungan dengan masalah yang dibahas.

c. Perancangan aplikasi. Tahap ini dilakukan perancangan struktur data melalui query yang dibuat, merancang form-form masukan dan form-form keluaran dengan menggunakan pemrograman java.

d. Pengkodeaan. Tahap ini dilakukan saat pengguna java Neatbeans dan menghubungkan datadata yang dibuat.

e. Pengujian sistem. Untuk menemukan kesalahan dan memastikan apakah semua fungsi sistem bekerja dengan baik.

\section{HASIL DAN PEMBAHASAN}

Dekomposissi Fungsi Sistem yang Berjalan

Dekomposisi fungsi sistem yang berjalan dalam sistem input data pada wilayah RT002/012 adalah sebagai berikut : 


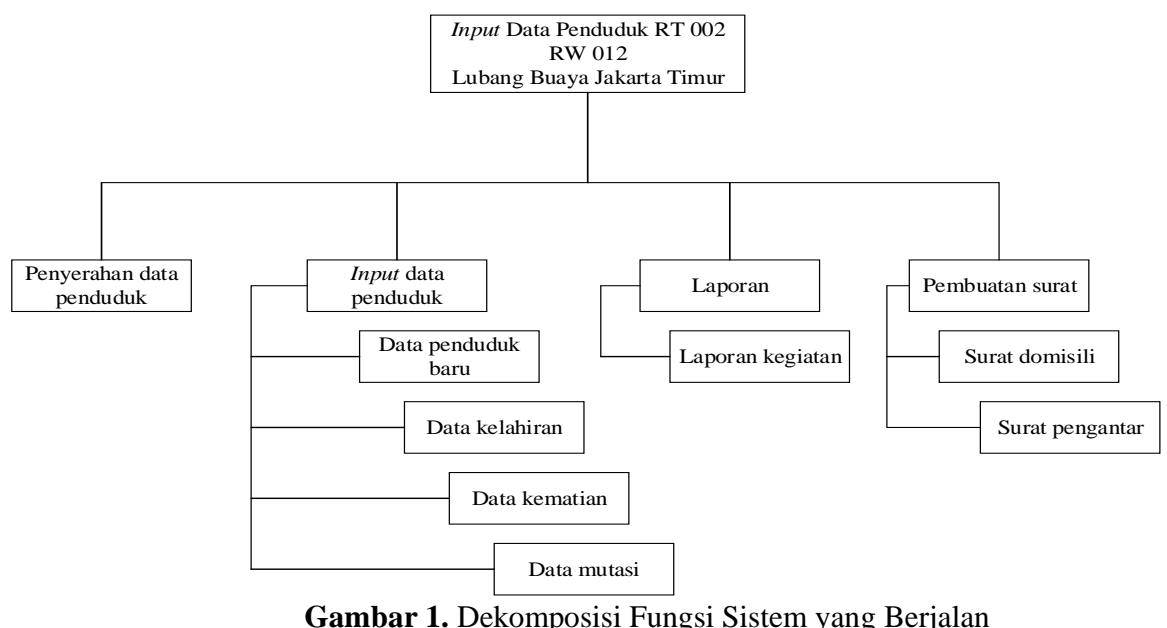

\section{Analisis Bisnis Sistem Yang Diusulkan}

Analisis bisnis sistem yang disusulkan menjelaskan bagaimana prosedur-prosedur yang berjalan di RT.002 RW.012 tentang pengelolaan data penduduk baru, pengelolaan kelahiran, pengelolaan kematian, pengelolaan mutasi, pengelolaan surat pengantar, dan pengelolaan surat domisili. Yang dilakukan petugas/sekertaris RT.

\section{Dekomposisi Fungsi Sistem yang Diusulkan}

Prosedur sistem yang diusulkan ini sebagian besar sama seperti sistem berjalan sebelumnya. Adapun dekomposisi fungsi sistem yang diusulkan pada wilayah RT 002 RW 012 sebagai berikut :

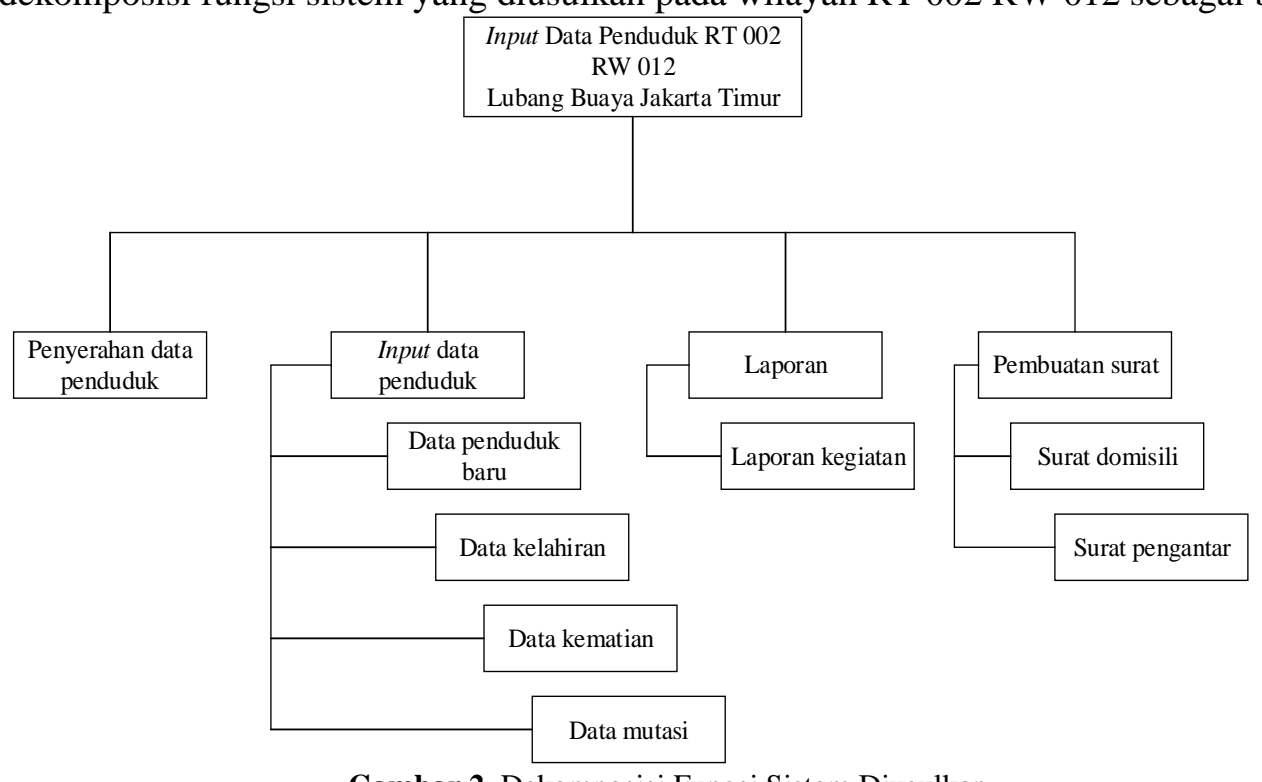

Gambar 2. Dekomposisi Fungsi Sistem Diusulkan

\section{Diagram Aliran Data (DAD) Sistem yang Diusulkan (Diagram Konteks, Diagram Nol.Diagram Rinci) \\ Diagram Konteks Sistem yang Diusulkan}

Berikut ini merupakan penggambaran tentang sistem yang diusulkan pada Perancangan Aplikasi Data Penduduk RT 002 RW 012 Lubang Buaya secara keseluruhan dalam bentuk diagram konteks. 


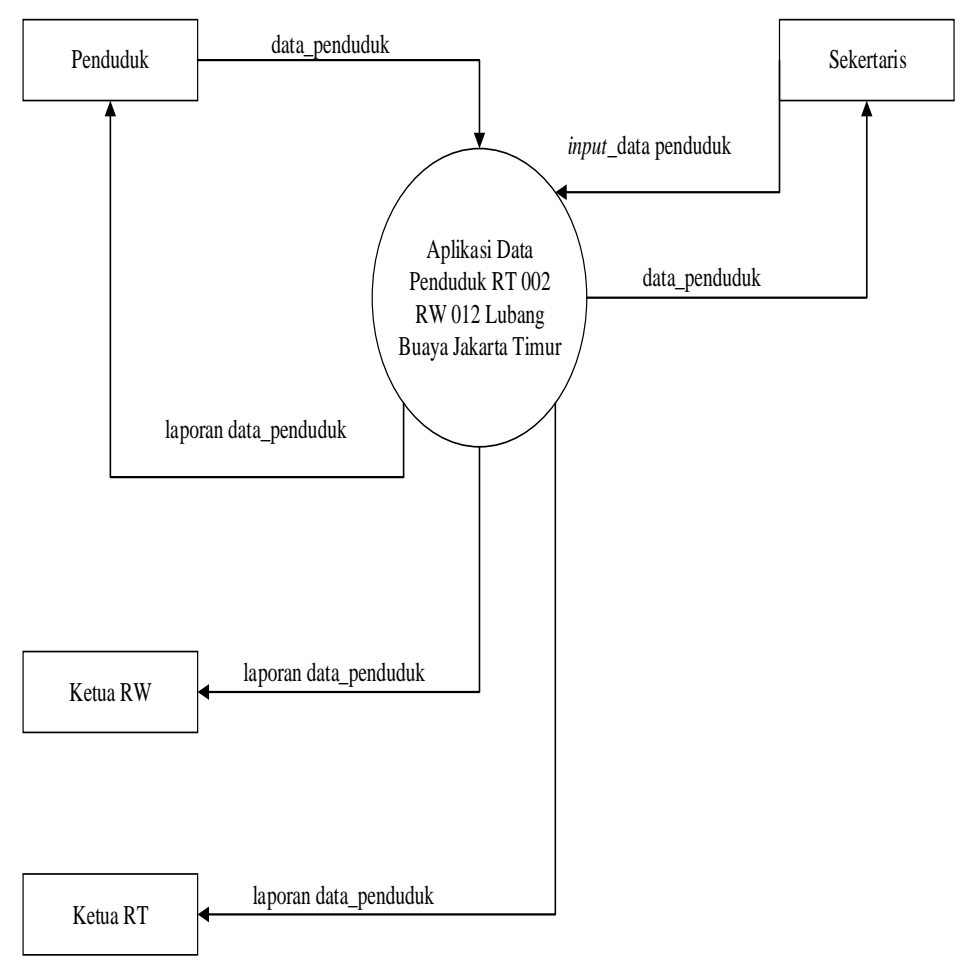

Gambar 3. Diagram Konteks sistem yang diusulkan

\section{Diagram Nol Sistem yang Diusulkan}

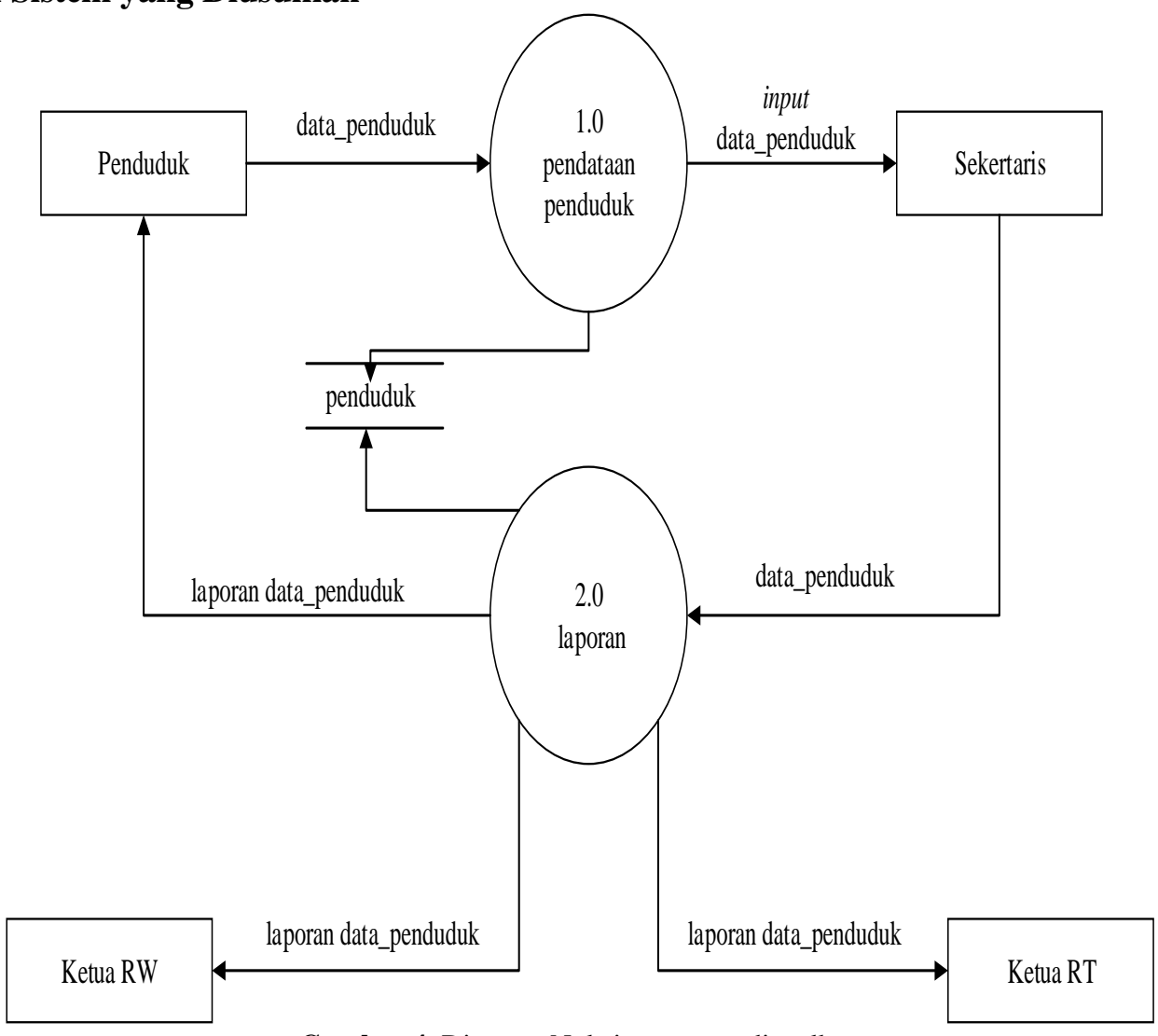

Gambar 4. Diagram Nol sistem yang diusulkan 


\section{Diagram Rinci 1 Sistem yang Diusulkan}

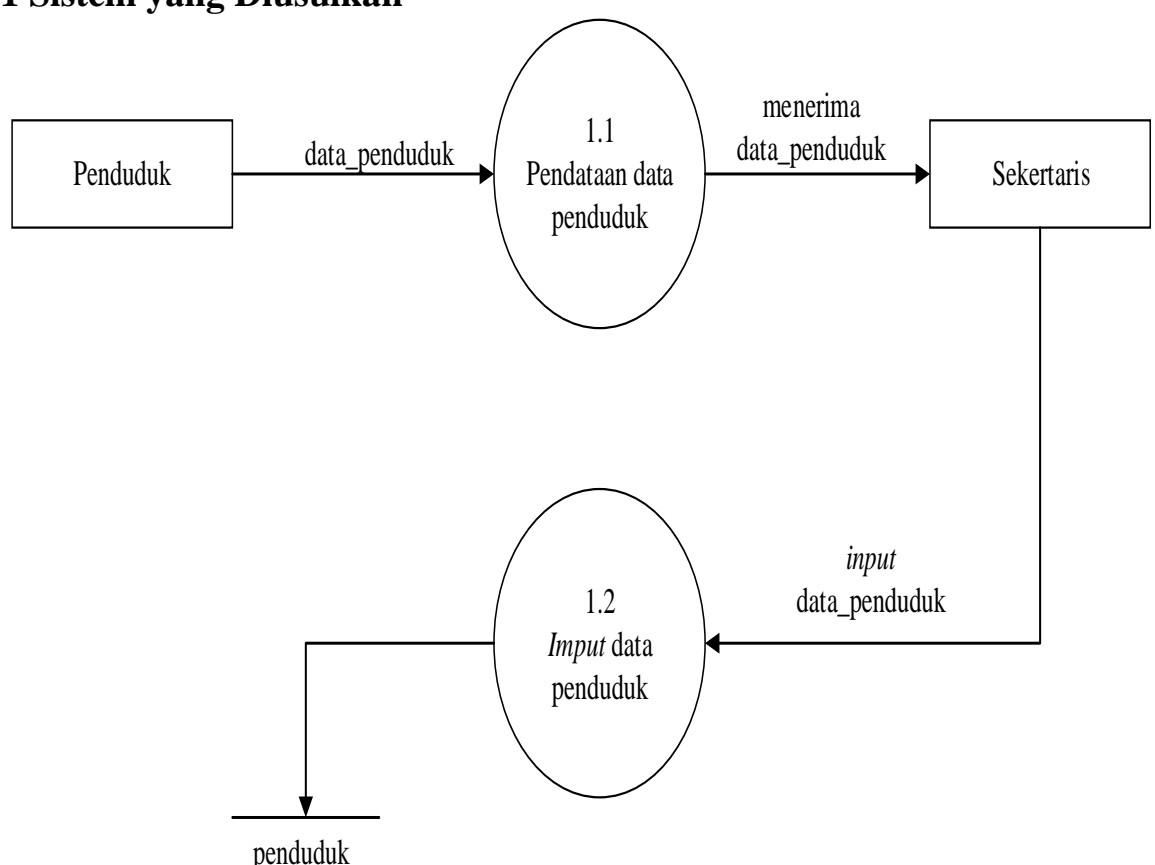

penduduk

Gambar 5. Diagram Rinci 1 sistem yang diusulkan

\section{Rancangan Basis Data Sistem yang Diusulkan}

Menurut Conolly dan Begg (2010:65), basis data adalah sebuah kumpulan data yang secara logis terkait dan dirancang untuk memenuhi suatu kebutuhan informasi dari sebuah organisasi.

\section{Relasi Tabel}

Proses relasi tabel merupakan pengelompokan data menjadi tabel-tabel yang menunjang entitas dan relasinya, yang berfungsi untuk mengakses data item sedemikian rupa sehingga database menjadi mudah dimodifikasi. Berikut adalah tabel relasi yang menghubungkan antar tabel.

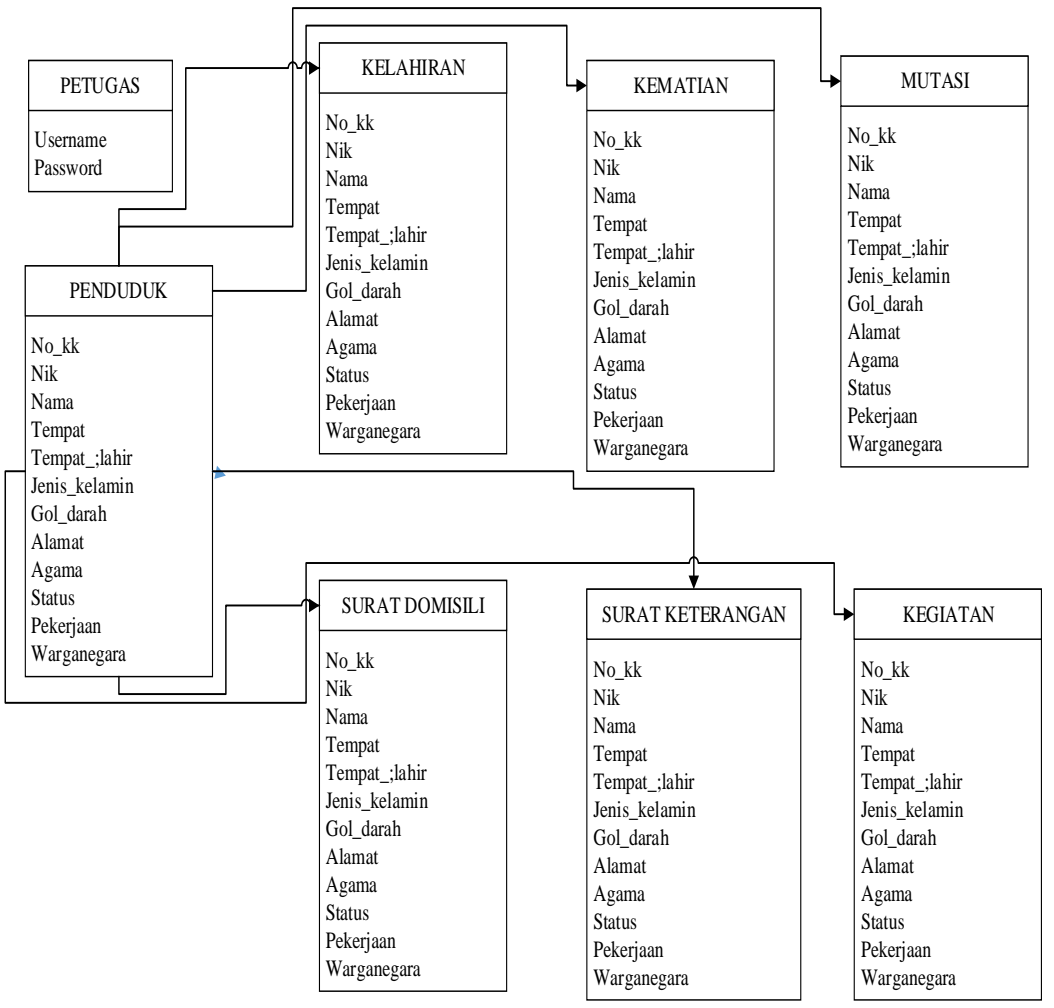

Gambar 6. Bentuk tabel relasi 


\section{Entity Relationship Diagram (ERD)}

Sukamto dan shalahuddin (2015:53), Entity Relationship Diagram (ERD) dikembangkan berdasarkan teori himpunan dalam bidang metematika dan bentuk awal dalam melakukan perancangan basis data relasional.

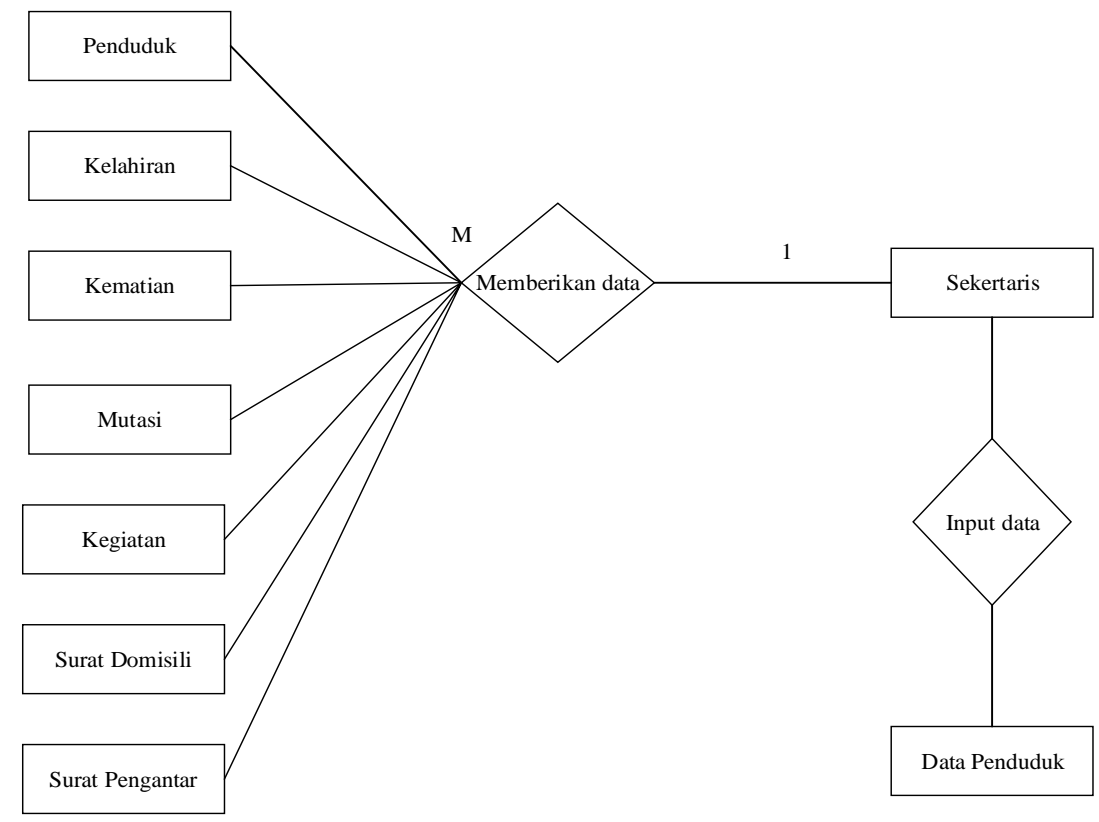

Gambar 7. Entity Relationship Diagram (ERD)

\section{Tampilan Sistem}

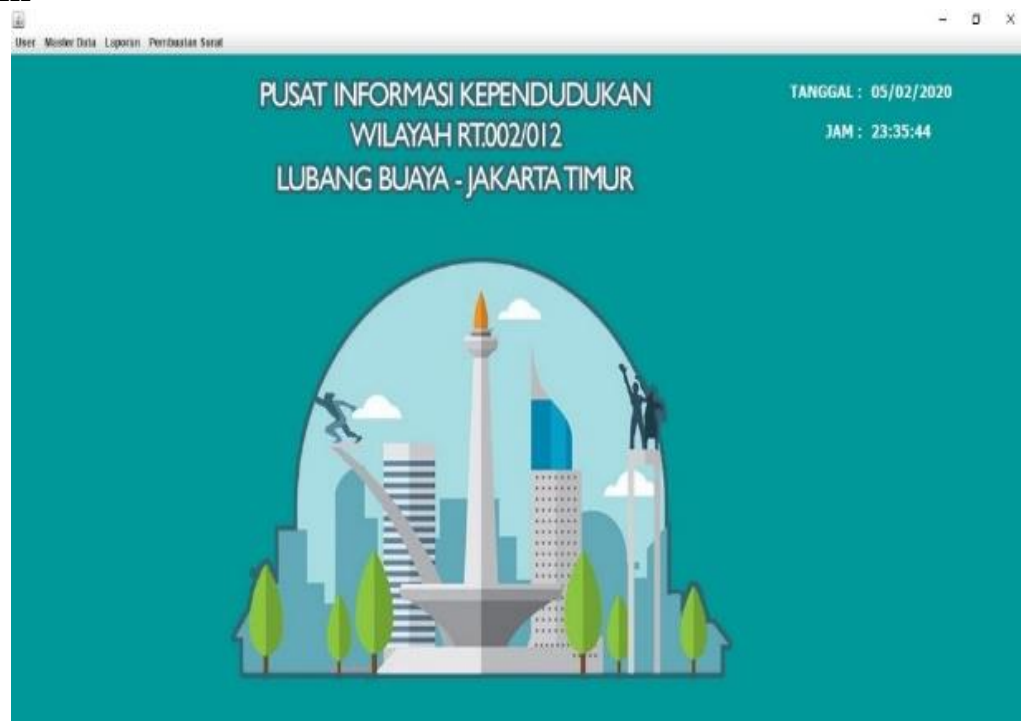

Gambar 8. Tampilan Form Menu Utama

Setelah login berhasil user akan langsung masuk ke menu utama, di menu ini terdapat beberapa pilihan menu diantaranya master data, laporan, dan permintaan surat.

\section{SIMPULAN}

Dengan dibuatnya sistem pelayanan kependudukan ini diharapkan dapat mempermudah pekerjaan petugas RT dalam pendataan kependudukan yang selama ini dikerjakan dengan sistem manual menjadi sistem yang terkomputerisasi. Berdasarkan uraian dan analisa diatas, maka laporan penelitian ini yang berjudul "Rancangan Sistem Aplikasi Kependudukan Di RT.002 RW.012 Lubang Buaya" dapat diambil kesimpulan sebagai berikut : Sistem Pelayanan Kependudukan ini sangat membantu dan memberikan kemudahan untuk penggunanya dalam pendataan kependudukan. Dengan adanya penyimpanan data yang sudah berbentuk database, maka dapat 
meminimalisir duplikasi data serta dapat mempersingkat waktu dalam pencarian data kependudukan.

\section{DAFTAR PUSTAKA}

Purba, Jhony (2012). Manajemen Project Sistem Informasi. Yogyakarta: Andi.

Sutabri, Tata. (2012). Konsep Dasar Informatika. Yogyakarta : Andi.

Jogiyanto,HM. (2009). Analisis dan Desain Sistem Informasi. Yogyakarta : Andi.

Sutabri, Tata. (2014). Konsep Dasar Informatika. Yogyakarta : Andi.

Kahfi, Gamal Abdul. (2018). Perancangan Aplikasi Dta Penduduk RT 04 RW 008 Perumahan Kemang Swatama Depok Berbasis Java.

Nurizal, Irwan (2014) Sistem Informasi Data Kependudukan dan Administrasi Di Kelurahan Curug Kecamatan Cimanggis.

Wahidin, Dede.(2017). Sistem Administrasi Kependudukan Berbasis Website Pada Desa Mariuk.

Supriyanto. (2015). Sistem Informasi Data Kependudukan Pada Kantor Kelurahan Desa Demangan Kabupaten Boyolali. Conolly dan Begg. (2010). Database Sytem. New York Harlow

Sukamto dan shalahuddin (2014). Rekayasa Perangkat Lunak Terstuktur dan Berorientasi Objek. Informatika Bandung : Bandung 